\title{
IMPACT OF GLOBAL AND LOCAL REACTIVITY DESCRIPTORS ON THE HETERO-DIELS-ALDER REACTION OF ENAMINOTHIONE WITH VARIOUS ELECTROPHILES
}

\author{
VINITA SAHU, ,+ PRATIBHA SHARMA, * ASHOK KUMAR \\ Department of Chemistry, Alliance College of Engineering and Design, Alliance University, Bangalore, Karnataka, India \\ (Received: May 30, 2013 - Accepted: December 16, 2013)
}

\begin{abstract}
The mechanism of the Diels-Alder reaction of 1-(2-furyl)-3-(dimethylamino)-2-propene-1-thione with various dienophiles resulting in the formation of $2 H$ thiopyran derivatives were discussed by evaluating global and local electrophilicity and nucleophilicity descriptors for whole series of diene and dienophiles at B3LYP/6-31G* level of theory. The results preluded that the polarity and charge transfer flow between diene and dienophiles was consistent with the global reactivity descriptors and substitutional pattern. The local descriptors based on Parr functions proposed by Domingo were found to be quite promising to explain the regioselectivity of cycloaddition processes. For symmetrical dienophiles viz., 2, 5, 8, 11a, 11b, 13 and 14 the local descriptors concentrates equally (50\%) at both interacting sites, to allocate non-regioselective cycloadditions. However, unsymmetrical dienophiles 16,18a-e and $\mathbf{2 1}$ have shown a preference towards a particular regioisomer and shown high regioselectivity during cycloaddition reaction. Regional nucleophilicity at the interacting site of diene were evaluated using local nucleophilicity descriptor $N_{k}$. These outcomes were found to be in exact correlation with the experimental outcomes achieved by Bogdanowicz et al.
\end{abstract}

Keywords: Enaminothione, DFT, B3LYP-6-31G*, global and local reactivity descriptors

\section{INTRODUCTION}

Hetero-Diels-Alder reactions are the most powerful available methodologies for the construction of six membered heterocyclic derivatives which have wide applications in the area of medicinal, computational and synthesis. In recent years, the chemistry of multiple bond compounds is quite interesting. Among these compounds the study of the behavior of carbon chalcogen double bonds $(-\mathrm{C}=\mathrm{S},-\mathrm{C}=\mathrm{O},-\mathrm{C}=\mathrm{Se}$ ) as dienes in hetero-Diels-Alder (HDA) reaction is worth important. ${ }^{1-6}$ In this regard, Bogdanowicz et al. ${ }^{7}$, has studied the DielsAlder reaction of 2-furyl substituted 1-thia-1, 3-butadiene with various electrophilic olefins affording 2 -furyl substituted $2 \mathrm{H}$-thiopyran derivatives with high stereo selectivity.

Density functional theory (DFT) has been quite successful in explaining theoretical background of molecular properties and chemical concepts. In this context, several reactivity descriptors have been proposed and used to analyze chemical reactivity and site selectivity. Global and local reactivity descriptors evaluated using DFT are very much useful in explaining the behavior of reactant and products in an organic reaction. In this regards global electrophilicity, ${ }^{8}$ chemical potential, ${ }^{9-10}$ global hardness, ${ }^{11-16}$ global softness, ${ }^{10,17}$ and nucleophilicity $^{18-20}$ are highly successful in predicting the feasibility and polarity of cycloaddition reactions. Fukui function and local electrophilicity/nucleophilicity are extensively applied to probe the local reactivity and site selectivity. Moreover, the local reactivity descriptors provide a deep insight about the regioselectivity of cycloaddition reactions. In this context, for a long time, Domingo's group has been involved in the study of the DA reactions using these parameters to establish the polar character of cycloaddition..$^{21-28}$ Moreover, recent literature study reveals that global and local descriptors are very useful and reliable tools for the predication of reaction mechanisms. ${ }^{29-33}$ Thus exploration of global and local reactivity descriptors to understand the mechanistic aspects for a cycloaddition reaction is worth important.

Therefore, keeping in view the importance of global and local reactivity descriptors, and in continuation of the work of Bogdanowicz et al. ${ }^{7}$, we have explored these parameters for the 1-(2-furyl)-3-(dimethylamino)-2-propene-1thione (diene) and various dienophiles and predicted the behavior of DielsAlder reaction to afford 2-furyl substituted $2 H$-thiopyrans. Furthermore, the regioselectivity of cycloaddition reaction was also predicted in view of local electrophilicity and nucleophilicity descriptors. The results were in excellent correlation with the experimental findings reported by Bogdanowicz et al. ${ }^{7}$

\section{Theoretical Background}

From recent DFT studies it has been evidenced that global and local electrophilicity parameters are important tools for predicting the feasibility, polar character and mechanistic aspects of Diels-Alder reaction. The global electrophilicity index $\omega^{8}\left(\omega=\mu^{2} / 2 \eta\right)$ measures the stabilization energy in the process of getting an additional electronic charge $\Delta N_{\max }$ from the environment. Here,
$\mu=(I+A) / 2$ and $\eta=(A-I)$ are the electronic chemical potential $\mu^{9-10}$ and chemical hardness $\eta^{11-16}$ of the ground state of atoms and molecules, respectively. These are approximated in terms of the vertical ionization potential $(I)$ and electron affinity $(A)$ using Koopman's theorem. ${ }^{34}$ The global softness, reciprocal of chemical hardness $S^{17}$ and local softness $s(k)^{35,10}$ can be expressed as: $S=(1 / 2)$ $\eta, s(k)=S f(k)$, respectively. Moreover, the maximum electronic charge $\Delta N_{\max } 8$ $\left(\Delta N_{\max }=-\mu / \eta\right)$ accounts for the maximum charge that an electrophile may accept from the environment. Furthermore, the partition for $\Delta N_{\max }$ in terms of the electrophilic/ nucleophilic Fukui function can be stated as follows: $\Delta N_{\max }(K)=$ $\Delta N_{\max } f_{k}^{+} / \Delta N_{\max } f_{k}^{-}$. The polar character of the interaction is described according to the proposed model by the difference in the absolute electrophilicity power $\Delta \omega{ }^{36}$ Further, the empirical nucleophilicity index, $N^{19}$, proposed by Kohn-Sham scheme ${ }^{18}$ based on the HOMO energies can be defined as

$$
N=E_{\text {номо(Nu) }}-E_{\text {Номо(TCE) }}
$$

Here, tetracyanoethylene (TCE) is taken as the reference in the nucleophilicity scale, because it presents lowest HOMO energy. This choice allows us to provide nucleophilicity scale with positive values.

Very recently, Domingo et al. ${ }^{37-39}$ have proposed a new local reactivity index, named Parr function $P(r)$, which is obtained from the ASD (atomic spin density) at the radical cation and at the radical anion of the corresponding reagents, which is given by the following equations,

$$
P^{-}(r)=\rho_{\mathrm{S}}{ }^{\mathrm{rc}}(\mathrm{r}) \text { for electrophilic attacks }
$$

and

$P^{+}(r)=\rho_{\mathrm{s}}^{\text {ra }}(\mathrm{r})$ for nucleophilic attacks

Where $\rho_{\mathrm{S}}{ }^{\mathrm{rc}}(\mathrm{r})$ is the ASD of the radical cation, and $\rho_{\mathrm{S}}^{\mathrm{ra}}(\mathrm{r})$ is the ASD of the radical anion.

With these electrophilic and nucleophilic Parr functions at hand, we can redefine the local electrophilicity $\omega_{k}$ and the local nucleophilicity $N_{k}^{39}$ indices as follows:

$$
N_{k}=N P_{k}
$$

Here maximum nucleophilicity power in a molecule will be developed at the site where nucleophilic Fukui function $N_{k}$ displays its maximum value. Beside the global electrophilicity index, it is possible to define its local counterpart i.e. local philicity $\omega_{k}{ }^{39,28}=\omega P_{k}^{+}$by considering the electrophilic Parr function $P_{k}^{+}$to characterize most electrophilic sites in molecule.

Thus, these global and local electrophilicity parameters are very significant and promising tools to gain a deep insight into the mechanistic details of DA reaction strategy. 


\section{Computational Details}

All the geometries included in this studies were fully optimized using the B3LYP/6-31G* level of theory ${ }^{40-43}$ using the Gaussian $03^{44}$ package of programs. The calculation of global electrophilicity parameters were done using equations given in theoretical section. The electronic chemical potential $\mu$ and chemical hardness $\eta$ values were approximated in terms of the one-electron energies of the HOMO and LUMO frontier molecular orbitals, $E_{H}(I)$ and $E_{L}(A)$, respectively using at the ground state (GS) of the molecules. The global maximum charge transfer that an electrophile may accept from the environment was evaluated using $\Delta N=-\mu / \eta$. Within this approach, the electrophilic and nucleophilic Fukui functions for electrophilic $\left(f_{k}^{-}\right)$and nucleophilic $\left(f_{k}^{+}\right)$attacks that were condensed to atoms or groups were evaluated from a single point calculation at the optimized structures of the GS of molecules by a method described elsewhere. ${ }^{45-46}$ Fukui functions were calculated using both the Mulliken population analysis (MPA) ${ }^{47}$ and natural population analysis (NPA) ${ }^{48-49}$ schemes, and only MPA results are reported in all of the cases. The local nu- cleophilicity index was calculated by $N_{k}=N P_{k}^{-}$relation. The electrophilic, $P_{k}^{+}$, and nucleophilic, $P_{k}^{-}$, Parr functions, were obtained through the analysis of the Mulliken ASD (Atomic Spin Density) of the radical anion and the radical cation by single-point energy calculations over the optimized neutral geometries using the B $3 \mathrm{LYP} / 6-31 \mathrm{G}^{*}$ level of theory.

\section{RESULTS AND DISCUSSIONS}

Reactivity of diene and dienophiles

Budzowski et al. $^{7}$ have synthesized 2-furyl substituted $2 \mathrm{H}$-thiopyrans derivatives by HDA reaction of enaminothione with various electrophilic olefins. In continuation of that work and to predict the mechanistic of the HDA reaction of enaminothione with various electrophilic olefins, we have evaluated various global and local electrophilicity parameters for whole series of diene and dienophiles and studied their interactions, polarity and charge transfer processes (Table $1 \& 2$ ).

Table 1. Structures of diene and dienophiles.

\begin{tabular}{|c|c|c|}
\hline $\begin{array}{c}\text { 1-(2-Furyl)-3-dimethylamino-2-propen-1- } \\
\text { thione }\end{array}$ & (2Z)-But-2-enedioic acid & $(2 E)$-But-2-enedioic acid \\
\hline Furan-2,5-dione & 1H-Pyrrole-2,5-dione & 1-Phenyl-1H-pyrrole-2,5-dione \\
\hline Diethyl (2Z)-but-2-enedioate & Diethyl (2Z)-but-2-enedioate & Furan-2(5H)-one \\
\hline [(E)-2-Nitroethenyl]benzene & 1-Methyl-4-[(E)-2-nitroethenyl]benzene & 1-Methoxy-4-[(E)-2-nitroethenyl]benzene \\
\hline 1-Chloro-4-[(E)-2-nitroethenyl]benzene & 1-Nitro-4-[(E)-2-nitroethenyl]benzene & $\underset{2-[(E)-2-\text { Nitroethenyl }] \text { furan }}{21}$ \\
\hline
\end{tabular}

1-(2-Furyl)-3-dimethylamino-2-propen-1-thione, diene $\mathbf{1}$ is having various dienic centers but it has been found that enaminothione dienic moiety participates in HDA reaction and the furan moiety exert electropositive effects to facilitate the cycloaddition process. The electrophilic index of $\mathbf{1}$ is very low and according to 
Domingo's electrophilicity scale ${ }^{36,50-51}$ it comes in the category of weak electrophile, therefore it can serve as a diene and can facilitate charge transfer flow from diene to dienophile in polar cycloaddition reaction. The nucleophilicity of $\mathbf{1}(N=4.01 \mathrm{eV})$ evidence its most nucleophilic nature towards dienophiles. Except dienophile $\mathbf{1 3}$ and $\mathbf{1 6}$ the electrophilicity $(\omega)$ for rest of the dienophiles (2-21) ranges from 1.92-3.63 eV, and as per Domingo's electrophilicity scale they comes in the category of strong electrophile and favor charge transfer flow from diene to dienophile in a polar cycloaddition reaction. Dienophile $\mathbf{1 3}$ $(\omega=1.70 \mathrm{eV})$ and $\mathbf{1 6}(\omega=1.55 \mathrm{eV})$ are less electrophilic than diene $\mathbf{1}(\omega=1.85$ $\mathrm{eV}$ ) which emphasizes on the reverse charge transfer flow from dienophile to diene. The electrophilicity difference is maximum for the interaction between
1 and 18e $(\Delta \omega=1.78 \mathrm{eV})$ and minimum for the interaction between $\mathbf{1}$ and 2 $(\Delta \omega=0.07 \mathrm{eV})$, which depends on the electrophilic nature of dienophile as well as the substituent pattern on reacting species. As the presence of $-\mathrm{NO}_{2}$ groups in 18e has a definite impact on electrophilicity and so on feasibility of cycloaddition reaction. Dienophiles $\mathbf{8 , 1 8 d}$ and $\mathbf{1 8 c}$ are comparatively strong dienophiles which can be explained by the presence of electronegative auxiliary groups viz., $\left(-\mathrm{NO}_{2},-\mathrm{C}=\mathrm{O},-\mathrm{O}-\right)$, these groups basically increases overall electrophilicity of the dienophile to facilitate better interactions with diene. On the contrary, dienophiles 2, $\mathbf{1 3}$ and $\mathbf{1 6}$ are least electrophilic in the given series that is due to the electropositive nature of the primary and auxiliary moieties. Furthermore, these results are also in accord with the practical findings.

Table 2. Calculated Global Electrophilicity Parameters $(\mathrm{eV})$ for Diene and Dienophiles

\begin{tabular}{|c|c|c|c|c|c|c|c|c|c|}
\hline Diene/Dienophile & HOMO I & LUMO A & $\mu$ & $\eta$ & $S$ & $\omega$ & $\Delta N_{\max }$ & $N$ & $\Delta \omega$ \\
\hline $\mathbf{1}$ & -5.11 & -1.85 & -3.48 & 3.27 & 0.15 & 1.85 & 1.07 & 4.01 & 0.00 \\
\hline $\mathbf{2}$ & -7.56 & -1.83 & -4.70 & 5.73 & 0.08 & 1.92 & 0.82 & 1.56 & 0.07 \\
\hline $\mathbf{5}$ & -7.82 & -2.50 & -5.16 & 5.32 & 0.09 & 2.51 & 0.97 & 1.29 & 0.65 \\
\hline $\mathbf{8}$ & -8.14 & -3.19 & -5.67 & 4.96 & 0.10 & 3.24 & 1.14 & 0.98 & 1.38 \\
\hline $\mathbf{1 1 a}$ & -7.46 & -2.72 & -5.09 & 4.73 & 0.11 & 2.73 & 1.08 & 1.66 & 0.88 \\
\hline $\mathbf{1 1 b}$ & -6.48 & -2.73 & -4.61 & 3.75 & 0.13 & 2.83 & 1.23 & 2.64 & 0.98 \\
\hline $\mathbf{1 3}$ & -7.24 & -1.55 & -4.39 & 5.69 & 0.09 & 1.70 & 0.77 & 1.88 & 0.16 \\
\hline $\mathbf{1 4}$ & -7.47 & -2.16 & -4.82 & 5.32 & 0.09 & 2.18 & 0.91 & 1.65 & 0.33 \\
\hline $\mathbf{1 6}$ & -7.39 & -1.30 & -4.35 & 6.09 & 0.08 & 1.55 & 0.71 & 1.73 & 0.30 \\
\hline $\mathbf{1 8 a}$ & -6.95 & -2.63 & -4.79 & 4.31 & 0.12 & 2.66 & 1.11 & 2.17 & 0.81 \\
\hline $\mathbf{1 8 b}$ & -6.72 & -2.54 & -4.63 & 4.18 & 0.12 & 2.56 & 1.11 & 2.40 & 0.71 \\
\hline $\mathbf{1 8 c}$ & -6.31 & -2.41 & -4.36 & 3.90 & 0.13 & 2.44 & 1.12 & 2.81 & 0.59 \\
\hline $\mathbf{1 8 d}$ & -6.98 & -2.82 & -4.90 & 4.16 & 0.12 & 2.88 & 1.18 & 2.14 & 1.03 \\
\hline $\mathbf{1 8}$ & -7.64 & -3.42 & -5.53 & 4.21 & 0.12 & 3.63 & 1.31 & 1.48 & 1.78 \\
\hline $\mathbf{2 1}$ & -6.57 & -2.62 & -4.60 & 3.96 & 0.13 & 2.67 & 1.16 & 2.54 & 0.82 \\
\hline
\end{tabular}

It is very interesting to notice the electrophilicity index for dienophile 13 (cis conformer) and $\mathbf{1 4}$ (trans conformer), the electrophilicity index $\omega$ is higher for $\mathbf{1 4}$ than $\mathbf{1 3}$, therefore $\mathbf{1 4}$ should react faster than $\mathbf{1 3}$ with diene $\mathbf{1}$, but it has been found experimentally by Budzowski et al. ${ }^{7}$ that $\mathbf{1 3}$ reacts faster than $\mathbf{1 4}$ which through a light on the importance of geometry and orientation of molecules for the participation in DA reaction. Though $\omega$ is higher for $\mathbf{1 4}$ and electrophilicity difference, $\Delta \omega$ is higher for the interaction between $\mathbf{1}$ and $\mathbf{1 4}$ rather than between $\mathbf{1}$ and 13, however $\mathbf{1 4}$ is in trans conformation which is less favorable orientation for Diels-Alder reaction thereby $\mathbf{1 3}$ reacts faster. Also included in Table 2 are the chemical potential $\mu$, the chemical hardness $\eta$, and the maximum charge transfer $\Delta N$. Note that the chemical potential and chemical hardness presents less clear pattern of variations with the groups. The maximum charge that each species may accept from the environment which is measured by $\Delta N_{\max }$, is almost parallel to the variation in electrophilicity for whole series of diene and dienophiles. Optimized geometries, ASD and ESP (Electrostatic potential) of diene and dienophiles are depicted in Table 3.

Table 3. Optimized geometries (B3LYP/6-311G*) with atom numbering, atomic spin densities (ASD) and ESP (electrostatic potential charge) of diene and dienophiles

\begin{tabular}{|l|c|c|c|}
\hline & Molecule & ASD & ESP* \\
\hline 1 & & &
\end{tabular}




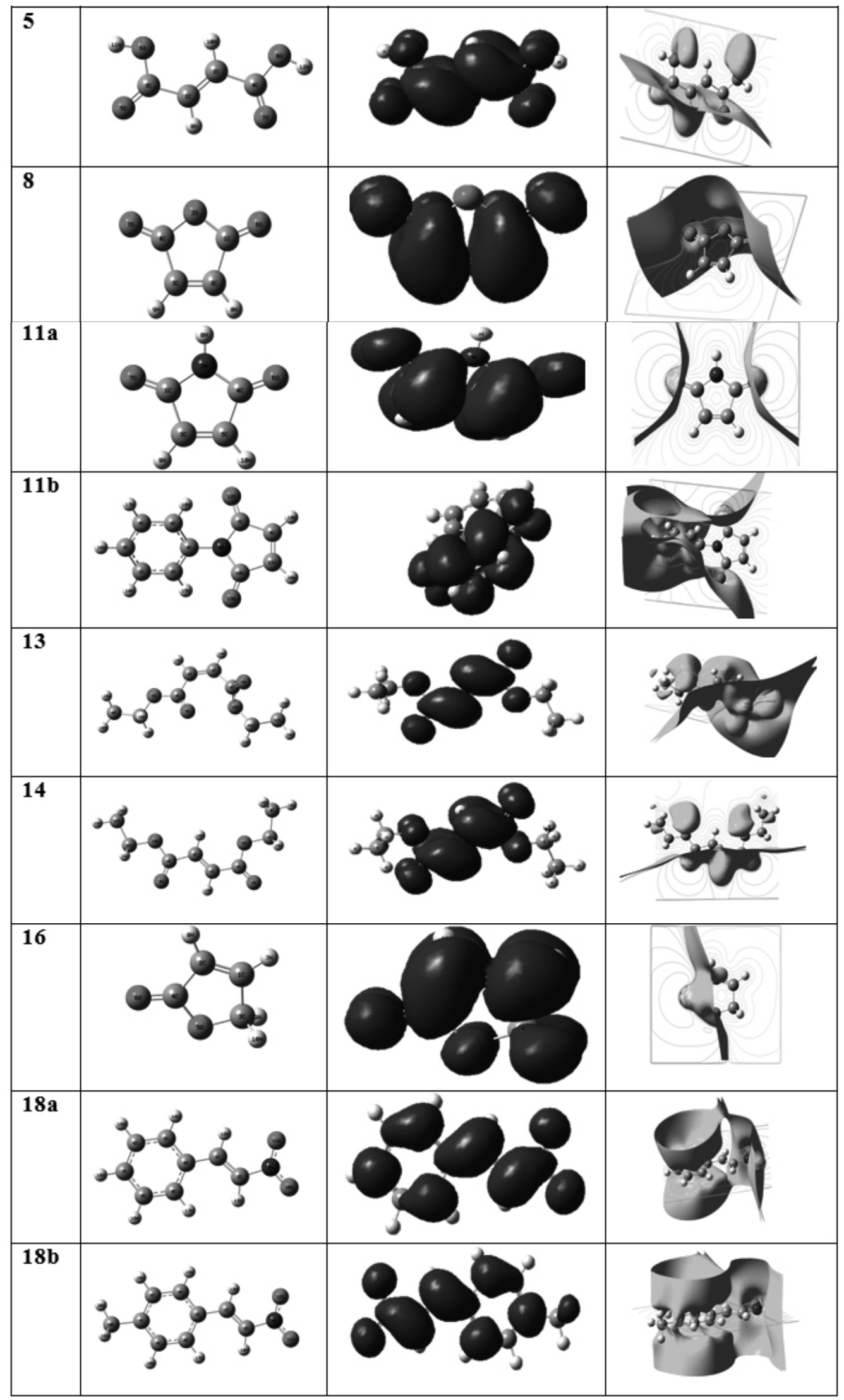




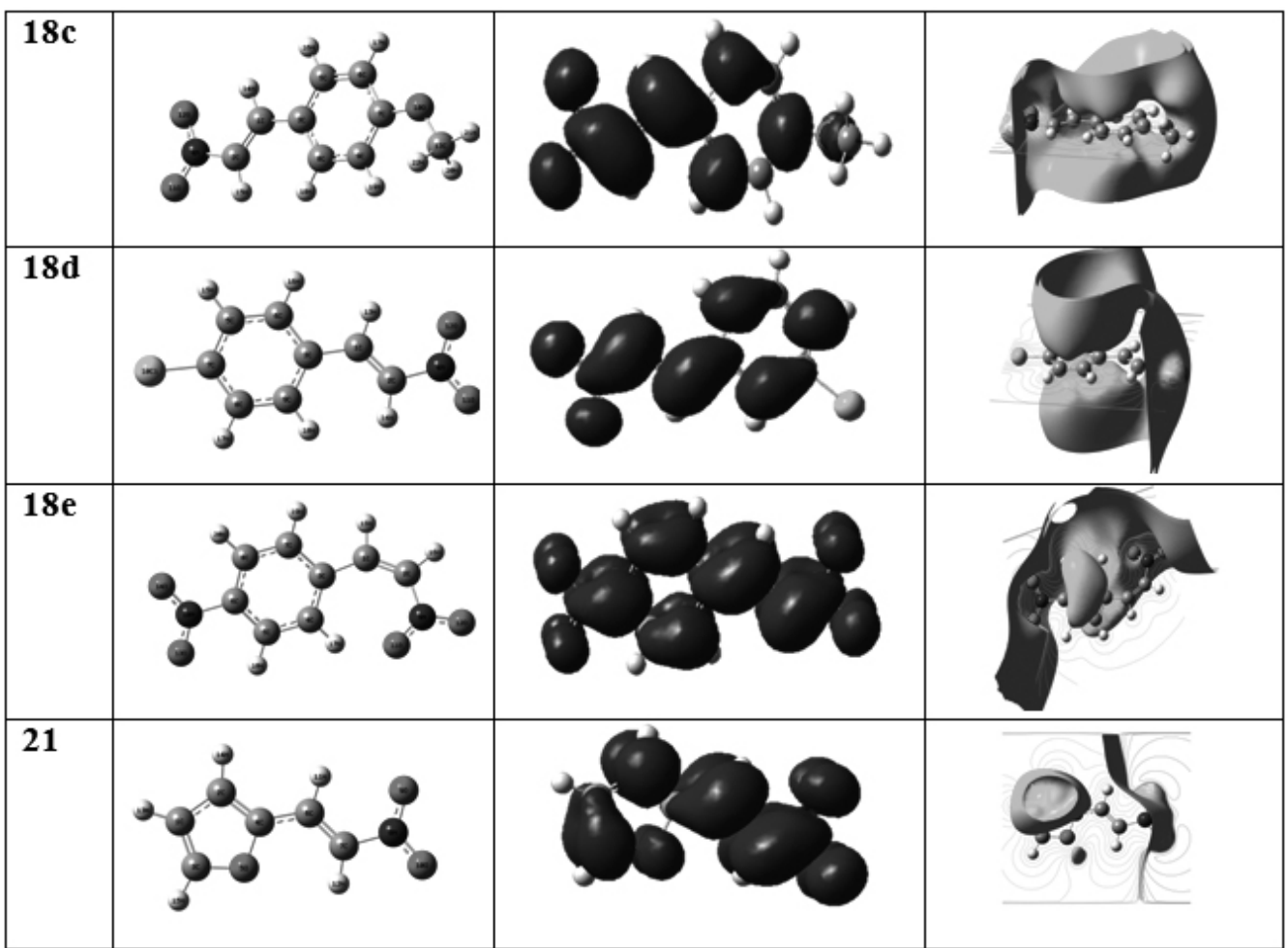

*Electrostatic potential (ESP) positive regions (red) correspond to electron-deficient areas - subject to nucleophilic attack; negative regions (blue) correspond to electron-rich areas - subject to electrophilic attack

\section{$-3.243 \mathrm{e} \cdot 2$}

A complete overview of various global electrophilicity parameters for diene and dienophiles 1-21 is depicted in Figure 1.

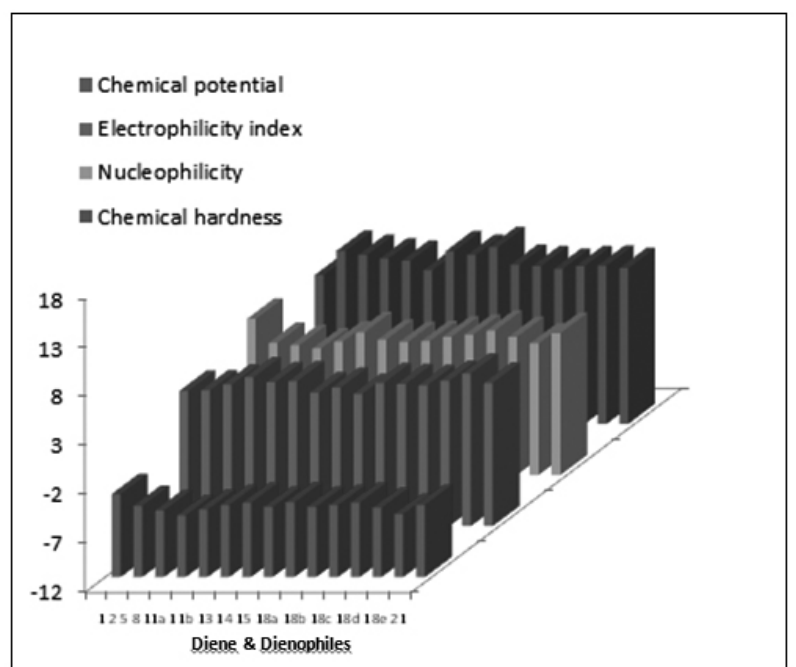

Figure 1. A comparative overview of global electrophilicity parameters $(\mathrm{eV})$ for diene and dienophiles

Moreover, multiple linear regression analysis has also been performed to correlate the electron affinity $(A)$ with electrophilicity index $(\omega)$ of dienophiles 2-21, and results (Figure 1) are interpreted in terms of statistical parameters, namely, standard deviation $(S D=0.07)$, regression coefficient $\left(r=0.99, r^{2}=\right.$ 0.98), etc., which were found to be quite promising.

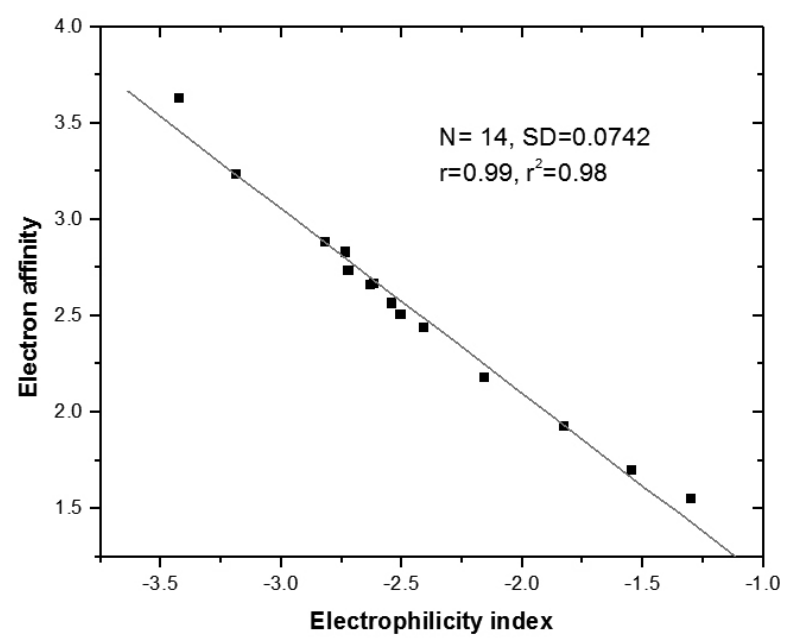

Figure 2. Plot of electrophilicity index $(\omega) v s$ electron affinity $(A)$ for dienophiles (2-21)

On this basis, it is clear that electron affinity $A$ and electrophilicity index $\omega$ are in excellent correlation with each other. Therefore, the global electrophilicity parameters are quite successful in explaining the experimental outcomes of the DA reaction.

\section{Regioselective studies}

The Parr functions proposed by Domingo et $a l^{37-39}$. have been computed for a series of substituted dienophiles and diene to elucidate the behavior of polar cycloaddition reactions. The study of Parr electrophilic index $\omega_{k}$ at electrophile, and analysis of Parr nucleophilic index $N_{t}$ at nucleophile gives an insight about the regioselectivity of cycloaddition reaction..$^{52-57}$ The local electrophilic and nucleophilic functions are summarized in Table $4 \& 5$ for diene and dienophiles respectively. 
Table 4. Local Properties ( $e V$ ) for Diene.

\begin{tabular}{|c|c|c|c|c|c|c|c|}
\hline Diene & & $f_{k}$ & $P_{k}^{-}$ & $N$ & $N_{k}$ & $\Delta N_{\max }$ & $\Delta N_{\max }(k)$ \\
\hline $\mathbf{1}$ & S-7 & 0.41 & 0.76 & 8.93 & 6.79 & 0.98 & 0.40 \\
\hline & C-9 & 0.02 & -0.05 & 8.93 & 0.45 & 0.98 & 0.02 \\
\hline
\end{tabular}

Table 5. Local Properties (eV) for Dienophiles.

\begin{tabular}{|c|c|c|c|c|c|c|c|}
\hline Dienophile & Site & $f_{k}^{+}$ & $P_{k}^{+}$ & $\omega$ & $\omega_{k}$ & $\Delta N_{\max }$ & $\Delta N_{\max }(k)$ \\
\hline \multirow[t]{2}{*}{2} & $\mathrm{C}-1$ & 0.06 & 0.27 & 1.92 & 0.52 & 0.82 & 0.05 \\
\hline & $\mathrm{C}-2$ & 0.06 & 0.27 & 1.92 & 0.52 & 0.82 & 0.05 \\
\hline \multirow[t]{2}{*}{5} & $\mathrm{C}-1$ & 0.06 & 0.27 & 2.51 & 0.68 & 0.97 & 0.06 \\
\hline & $\mathrm{C}-2$ & 0.06 & 0.26 & 2.51 & 0.65 & 0.97 & 0.06 \\
\hline \multirow[t]{2}{*}{8} & $\mathrm{C}-3$ & 0.08 & 0.26 & 3.24 & 0.84 & 1.14 & 0.09 \\
\hline & $\mathrm{C}-5$ & 0.08 & 0.26 & 3.24 & 0.84 & 1.14 & 0.09 \\
\hline \multirow[t]{2}{*}{$11 \mathrm{a}$} & $\mathrm{C}-3$ & 0.07 & 0.25 & 2.73 & 0.68 & 1.08 & 0.08 \\
\hline & $\mathrm{C}-5$ & 0.07 & 0.25 & 2.73 & 0.68 & 1.08 & 0.08 \\
\hline \multirow[t]{2}{*}{$11 \mathrm{~b}$} & $\mathrm{C}-3$ & 0.07 & 0.24 & 2.83 & 0.68 & 1.23 & 0.08 \\
\hline & $\mathrm{C}-5$ & 0.07 & 0.24 & 2.83 & 0.68 & 1.23 & 0.08 \\
\hline \multirow[t]{2}{*}{13} & C-1 & 0.01 & 0.25 & 1.70 & 0.43 & 0.77 & 0.01 \\
\hline & $\mathrm{C}-2$ & 0.01 & 0.26 & 1.70 & 0.44 & 0.77 & 0.01 \\
\hline \multirow[t]{2}{*}{14} & $\mathrm{C}-1$ & 0.07 & 0.26 & 2.18 & 0.57 & 0.91 & 0.06 \\
\hline & $\mathrm{C}-2$ & 0.07 & 0.25 & 2.18 & 0.55 & 0.91 & 0.06 \\
\hline \multirow[t]{2}{*}{16} & $\mathrm{C}-1$ & 0.11 & 0.62 & 1.55 & 0.96 & 0.71 & 0.08 \\
\hline & C-2 & 0.06 & 0.10 & 1.55 & 0.16 & 0.71 & 0.05 \\
\hline \multirow[t]{2}{*}{$18 \mathrm{a}$} & C-1 & 0.08 & 0.29 & 2.66 & 0.77 & 1.11 & 0.09 \\
\hline & $\mathrm{C}-2$ & 0.01 & 0.06 & 2.66 & 0.16 & 1.11 & 0.01 \\
\hline \multirow[t]{2}{*}{$18 \mathrm{~b}$} & $\mathrm{C}-1$ & 0.08 & 0.29 & 2.56 & 0.74 & 1.11 & 0.09 \\
\hline & $\mathrm{C}-2$ & 0.01 & 0.06 & 2.56 & 0.15 & 1.11 & 0.01 \\
\hline \multirow[t]{2}{*}{$18 \mathrm{c}$} & C-1 & 0.08 & 0.29 & 2.44 & 0.71 & 1.12 & 0.09 \\
\hline & C-2 & 0.00 & 0.06 & 2.44 & 0.15 & 1.12 & 0.00 \\
\hline \multirow[t]{2}{*}{$18 d$} & C-1 & 0.08 & 0.26 & 2.88 & 0.75 & 1.18 & 0.09 \\
\hline & C-2 & 0.01 & 0.09 & 2.88 & 0.26 & 1.18 & 0.01 \\
\hline \multirow[t]{2}{*}{$18 \mathrm{e}$} & C-1 & 0.06 & 0.11 & 3.63 & 0.40 & 1.31 & 0.08 \\
\hline & C-2 & 0.02 & 0.12 & 3.63 & 0.44 & 1.31 & 0.03 \\
\hline \multirow[t]{2}{*}{21} & C-6 & 0.07 & 0.31 & 2.67 & 0.83 & 1.16 & 0.08 \\
\hline & $\mathrm{C}-7$ & 0.02 & 0.04 & 2.67 & 0.11 & 1.16 & 0.02 \\
\hline
\end{tabular}

Diene $\mathbf{1}$ is unsymmetrical and having different local nucleophilicity values at interacting termini, thus can participate in regioselective cycloaddition with unsymmetrical dienophiles. Diene $\mathbf{1}$ is having two interacting nucleophilic centers S-7 and C-9. It has been evidenced from the data (Table 2) that S-7 site is more nucleophilic than C-9 (S-7, $\left.N_{k}=6.79, \mathrm{C}-9, N_{k}=0.45\right)$. Moreover, dienophiles $\mathbf{2}, \mathbf{5}, \mathbf{8}, \mathbf{1 1 a}, \mathbf{1 1 b}, \mathbf{1 3}$ and $\mathbf{1 4}$ are symmetrical dienophiles, therefore for these dienophiles there will be no regioselective addition, and in reaction only one cycloadduct is expected and found experimentally so ${ }^{7}$ (Scheme 1).

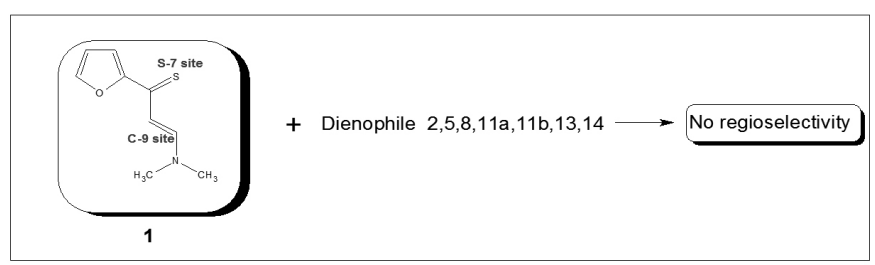

Scheme 1. Hetero-Diels-Alder reaction of diene 1 with symmetrical dienophiles
The cycloaddition of diene $\mathbf{1}$ to unsymmetrical dienophile $\mathbf{1 6}$ i.e., $2(5 H)$ furanone afforded only one regioisomers $\mathbf{1 7}$. Since the dienophile 16 is unsymmetrical it is having different local electrophilic index $\omega_{k}$ at the reacting termini i.e. $\mathrm{C}-1, \omega_{k}=0.96 \mathrm{C}-2, \omega_{k}=0.16$, therefore site $\mathrm{C}-1$ is more electrophilic and more susceptible towards nucleophilic attack consequently it will interact with most nucleophilic termini of diene $\mathbf{1}$ i.e., $\mathrm{S}-7$ to afford preferred regioisomer $17^{7}$ in $66 \%$ yield (Scheme 2).

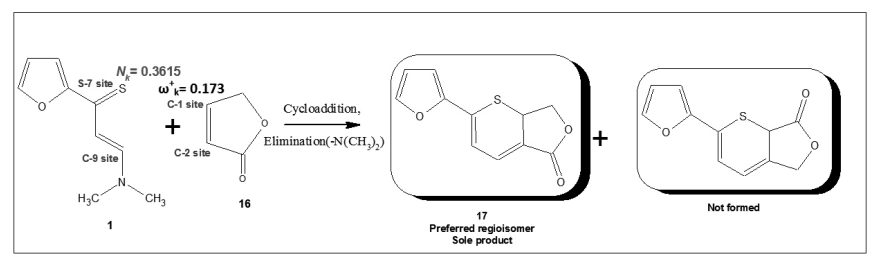

Scheme 2. Hetero-Diels-Alder reaction of diene 1 with 16. 
Reaction of diene $\mathbf{1}$ with unsymmetrical $\beta$-nitrostyrene derivatives 18a-e in acetonitrile at room temperature furnished only preferred regioisomers 19a$\mathbf{e}^{7}$, and then in next step elimination of amino dimethyl moiety affords 20a-e as sole regioisomers in good yields (Scheme 3). Dienophiles 18a-e are unsymmetrical dienophiles and there are the possibilities of formation of regioisomers but both experimentally and theoretically we obtained single regioisomers which can be evidenced by taking local electrophilic index $\omega_{k}$ into consideration. For dienophiles 18a-e the $\omega_{k}$ is higher at C-1 than C-2, it shows C-1 is more electrophilic than $\mathrm{C}-2$ termini and more prone towards nucleophilic attack of S-7 site by diene, therefore single regioisomers $20 \mathrm{a}-\mathbf{e}$ were obtained as the preferred product.

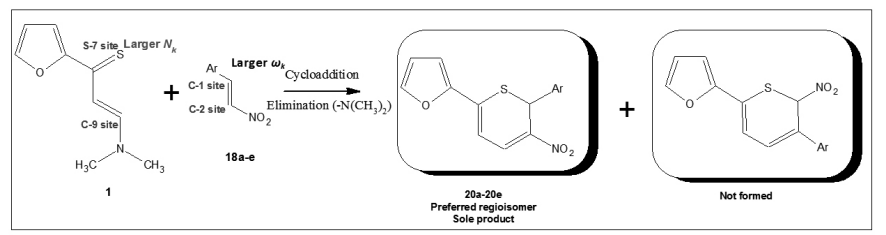

Scheme 3. Hetero-Diels-Alder reaction of diene $\mathbf{1}$ with $\mathbf{1 8 a - e}$

Similarly, 2-[(E)-2-Nitroethenyl] furan, dienophile $\mathbf{2 1}$ is an unsymmetrical dienophile having more electrophilicity at C-6 $\left(\omega_{k}=0.83\right)$ than C-7 $\left(\omega_{k}=0.11\right)$ thereby C-6 site of $\mathbf{2 1}$ reacts preferably with S-7 site of diene $\mathbf{1}$ in a regioselective manner and results in the formation of only one regioisomer $\mathbf{2 2}$, which further undergoes amino dimethyl elimination to afford resulting product as red crystals (Scheme 4). These results are in exact consistence with experimental observations also. The local electrophilic index at different interacting sites for a series of dienophiles is depicted in Figure 3.

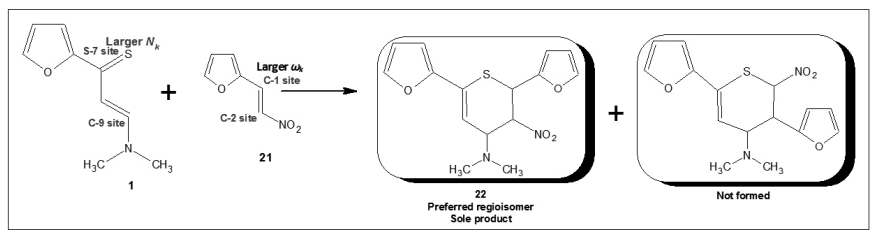

Scheme 4. Hetero-Diels-Alder reaction of diene $\mathbf{1}$ with $\mathbf{2 1}$

Another remarkable result follows from the maximum charge transfer described by the $\Delta \mathrm{N}_{\text {ix }}(k)$ quantity, which presents the maximum propensity of the system to acquire additional electronic charge from the environment. The $\Delta \mathrm{N} \quad(k)$ value follows exactly the same pattern as local descriptor $\omega_{k}$ to assess the site selectivity in the DA reaction. For instance, unsymmetrical dienophiles 16, 18a-e, and 21 exhibit maximum $\Delta \mathrm{N} \quad(k)$ at $\mathrm{C}-1$ and $\mathrm{C}-6$ rather than $\mathrm{C}-2$ and C-7 for 16, 18a-e and 21 respectively. On the other hand, for symmetrical dienophiles 2, 5, 8, 11a, 11b, 13 and 14 the descriptor $\Delta N_{\text {max }}(k)$ concentrates equally (50\%) at both sites, C-1 and C-2; C-6 and C-7, to allocate non-regioselective cycloadditions. Thus for unsymmetrical dienophiles the most favorable interaction would be between S-7 of $\mathbf{1}$ and C-1 termini of dienophiles $\mathbf{1 6}$ and 18a-e, whereas for $\mathbf{2 1}$ the favorable interaction termini would be S-7 of diene and C-6 of dienophile to afford preferred regioisomers 20a-e and $\mathbf{2 2}$ in quantitative yields, respectively.

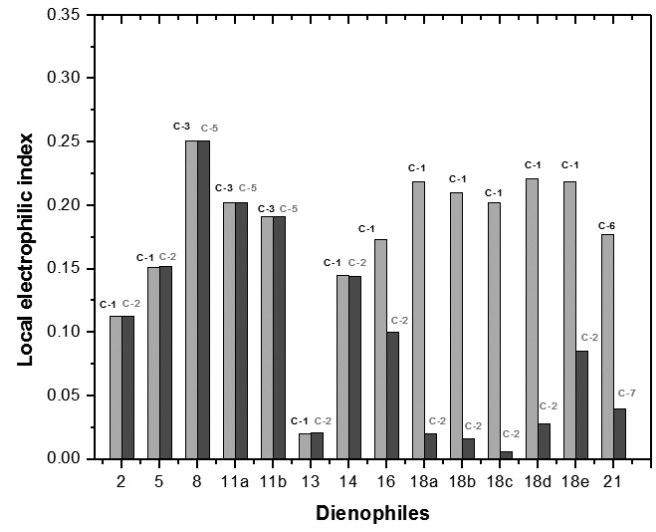

Figure 3. Plot of local electrophilicity index $\omega_{k}$ at C-a and C-b sites for a series of dienophiles.
Moreover, these computational results were found to be in exact correlation with experimental outcomes. Thus, conclusively these studies have successfully explained the regioselective behavior of diene and dienophiles in Diels-Alder reaction.

\section{CONCLUSIONS}

Conclusively, global and local reactivity descriptors were evaluated to interpret mechanism, charge transfer direction and regioselectivity of DielsAlder reaction of enaminothiones with various electrophiles to afford $2 \mathrm{H}$ thiopyran derivatives. The electrophilicity hierarchy, namely, electrophilicity index, chemical potential, chemical hardness, softness, $\Delta N_{\max }$, etc., were found in good agreement with substitution pattern on diene and dienophiles. The prediction of regioselectivity for symmetrical and unsymmetrical dienophiles was as par the local reactivity descriptors and was found to be in exact agreement with the experimental findings observed by Budzowski et al. ${ }^{7}$ Thus these descriptors have successfully explained the behavior, reactivity and regioselectivity of diene and dienophiles in a cycloaddition reaction. Hence it is concluded that there is an ample scope in evaluating these descriptors for the better understandings of cycloaddition reactions.

\section{ACKNOWLEDGEMENTS}

We would like to thanks the reviewers for their fruitful suggestions and valuable inputs to improve the standard of manuscript.

\section{REFERENCES}

1. L. F. Tietze, G. Kattschau Topics in Current Chemistry 189, Stereoselective Heterocyclic Synthesis I, P. Metz, Ed. Springer, Berlin 1997; pp. $1-120$.

2. L. F.Tietze, U. Harfiel, T. Hubsch, E. Voß, K. Bogdanowicz- Szwed, J. Wichmann, Liebigs Ann. Chem. 275, (1991).

3. K. Bogdanowicz-Szwed, A. Palasz, Monatsh. Chem. 126, 1341, (1995).

4. K. Bogdanowicz-Szwed, A. Palasz, Monatsh. Chem. 128, 1157, (1997).

5. K. Bogdanowicz-Szwed, A. Palasz, Monatsh. Chem. 130, 795, (1999).

6. K. Bogdanowicz-Szwed, A. Palasz, Monatsh. Chem. 132, 947, (2001).

7. K. Bogdanowicz-Szwed, A. Budzowski, Z. B. Naturforsch: J. Chem. Sci. 57b, 637, (2002).

8. R. G. Parr, L.v. Szentpaly, S. Liu, J. Am. Chem. Soc. 121,1922, (1999).

9. R. G. Parr, D. A. Donnelly, M. Levy, W. E. Palke, J. Chem. Phys. 68, 3801, (1978).

10. R. G. Parr, W. Yang Density Functional Theory of Atoms and Molecules; Oxford University Press, Oxford, NY, 1989.

11. R. G. Pearson, J. Am. Chem. Soc. 85, 3533, (1963).

12. R. G. Parr, R. G. Pearson, J. Am. Chem. Soc. 105, 7512, (1983).

13. P. K. Chattaraj, H. Lee, R. G. Parr, J. Am. Chem. Soc. 113, 1855, (1991).

14. P. K. Chattaraj, P. V. R. Schleyer, J. Am. Chem. Soc. 116, 1067, (1994).

15. P. K. Chattaraj, B. Maiti, J. Am. Chem. Soc. 125, 2705, (2003).

16. R. G. Pearson Chemical Hardness, Applications from Molecules to Solids, Wiley-VCH Verlag GMBH, Weinheim, 1997.

17. M. Berkowitz, S. K. Ghosh, R. G. Parr, J. Am. Chem. Soc. 107, 6811, (1985).

18. W. Kohn, L. Sham, Phys. Rev. 140, 1133, (1965).

19. L. R. Domingo, E. Chamorro, P. Perez, J. Org. Chem. 73, 4615, (2008).

20. P. Perez, L. R. Domingo, M. Duque-Norena, E. Chamorro, J. Mol. Struct. 895, 86, (2009).

21. L. R. Domingo, R. A. Jones, M. T. Picher, J. Sepulveda-arques, Tetrahedron 51, 8739, (1995).

22. L. R. Domingo, M. T. Picher, J. Andres V. Moliner, V. S. Safont, Tetrahedron 52, 10693, (1996).

23. L.R. Domingo, M.T. Picher, J. Andres, V.S. Safont, J. Org. Chem. 62, 1775 (1997).

24. L.R. Domingo, M.T. Picher, R.J. Zaragoza, J. Org. Chem. 63, 9183, (1998).

25. L. R. Domingo, M.T. Picher, M.J. Aurell, J. Phys. Chem. A 103, 11425 , (1999).

26. L.R. Domingo, Eur. J. Org. Chem. 4788, (2004).

27. L.R. Domingo, E. Chamorro, P. Perez, J. Phys. Chem. A 112, 4046, (2008).

28. L.R. Domingo, M.J. Aurell, R. Contreras, P. Perez, J. Phys. Chem. A 106, 6871, (2002).

29. P. Sharma, A. Kumar, V. Sahu, J. Phys. Chem. A 114, 1032, (2010).

30. P. Sharma, A. Kumar, V. Sahu, Lett. Org. Chem. 8, 132, (2011). 
31. P.K. Chattaraj, S. Giri, S. Duley, Chem. Rev. 111 (2), PR43, (2011).

32. J. Soto-Delgado, L.R. Domingo, R. Contreras, Org. Biomol. Chem. 8, $3678,(2010)$.

33. L.R. Domingo, R.J. Zaragoza, J.A. Saez, M. Arno, Molecules 17, 1335, (2012).

34. T.A. Koopmans, Physica 1, 104, (1933).

35. W. Yang, R.G. Parr, Proc. Natl. Acad. Sci. U.S.A. 82, 6723, (1985).

36. L.R. Domingo, M.J. Aurell, P. Perez, R. Contreras, Tetrahedron 58, 4417, (2002).

37. L.R. Domingo, P. Perez, J.A. Saez, Org. Biomol. Chem. 10, 3841, (2012).

38. L.R. Domingo, P. Perez, J.A. Saez, Tetrahedron 69, 107, (2013).

39. L.R. Domingo, P. Perez, J.A. Saez, RSC Adv. 3, 1486, (2013).

40. A.D. Becke, Phys. Rev. A 38, 3098, (1998).

41. C. Lee, W. Yang, R.G. Parr, Phys. Rev. B 37, 785, (1988).

42. P.C. Hariharan, J.A. Pople, Thermochim. Acta 28, 213, (1973).

43. A.D. Becke, J. Chem. Phys. 98, 5648, (1993).

44. M.J. Frisch, G.W. Trucks, H.B. Schlegel, G.E. Scuseria, M.A. Robb, J.R Cheeseman, J.A. Montgomery, T. Vreven, K.N. Kudin, J.C. Burant, J.M. Millam, S.S. Iyengar, J. Tomasi, V. Barone, B. Mennucci, M. Cossi, G. Scalmani, N. Rega, G.A. Petersson, H. Nakatsuji, M. Hada, M. Ehara, K. Toyota, R. Fukuda, J. Hasegawa, M. Ishida, T. Nakajima, Y. Honda, O. Kitao, H. Nakai, M. Klene, X. Li, J.E. Knox, H.P. Hratchian, J.B. Cross, V. Bakken, C. Adamo, J. Jaramillo, R. Gomperts, R.E. Stratmann, O. Yazyev, A.J. Austin, R. Cammi, C. Pomelli, J.W. Ochterski, P.Y. Ayala, K. Morokuma, G.A. Voth, P. Salvador, J.J. Dannenberg, V.G. Zakrze- wski, S. Dapprich, A.D. Daniels, M.C. Strain, O. Farkas, D.K. Malick, A. D. Rabuck, K. Raghavachari, J.B. Foresman, J.V. Ortiz, Q. Cui, A.G. Baboul, S. Clifford, J. Cioslowski, B.B. Stefanov, G. Liu, A. Liashenko, P. Piskorz, I. Komaromi, R.L. Martin, D.J. Fox, T. Keith, M.A. Al-Laham, C.Y. Peng, A. Nanayakkara, M. Challacombe, P.M. W. Gill, B. Johnson, W. Chen, M.W. Wong, C. Gonzalez, J.A. Pople, Gaussian 03W, revision B.03; Gaussian, Inc.: Pittsburgh, PA, 2003.

45. R. Contreras, P. Fuentealba, M. Galvan, P. Perez, Chem. Phys. Lett. 304, 405, (1999)

46. P. Fuentealba, P. Perez, R. Contreras, J. Chem. Phys. 113, 2544, (2000).

47. R.S. Mulliken, J. Chem. Phys. 23, 1833, (1955).

48. A.E. Reed, R.B. Weinstock, F. Weinhold, J. Chem. Phys. 83, 735, (1985).

49. A.E. Reed, F. Weinhold, J. Chem. Phys. 78, 4066, (1983).

50. P. Perez, L.R. Domingo, A. Aizman, R. Contreras The Electrophilicity Index in Organic Chemistry. In Theoretical Aspects of Chemical Reactivity, Toro-Labbe, A. Ed. Elsevier Science: New York, vol 19, ch 9; pp. $139,2007$.

51. L.R. Domingo, J.A. Saez, Org. Biomol. Chem. 7, 3576, (2009).

52. L.R. Domingo, Tetrahedron 58, 3765, (2002).

53. L.R. Domingo, M.J. Aurell, P. Perez, R. Contreras, J. Org. Chem. 68, 3884, (2003).

54. L.R. Domingo, J. Andres, J. Org. Chem. 68, 8662, (2003).

55. P. Perez, L.R. Domingo, M.J. Aurell, R. Contreras, Tetrahedron 59, 3117 , (2003).

56. A. Saez, M. Arno, L.R. Domingo, Tetrahedron 59, 9167, (2003).

57. L.R. Domingo, M.T. Picher, Tetrahedron 60, 5053, (2004). 